\title{
Recent progress in dengue vaccine development
}

\author{
Jianchun Wei, Hui Chen ${ }^{\otimes}$, Jing $A n^{凶}$ \\ Department of Microbiology, School of Basic Medical Sciences, Capital Medical University, Beijing 100069, \\ China
}

Dengue virus (DENV) has four distinct serotypes. DENV infection can result in classic dengue fever and life-threatening dengue hemorrhagic fever/dengue shock syndrome. In recent decades, DENV infection has become an important public health concern in epidemic-prone areas. Vaccination is the most effective measure to prevent and control viral infections. However, several challenges impede the development of effective DENV vaccines, such as the lack of suitable animal models and the antibody-dependent enhancement phenomenon. Although no licensed DENV vaccine is available, significant progress has been made. This review summarizes candidate DENV vaccines from recent investigations.

\section{KEYWORDS dengue virus; vaccine; dengue fever; flavivirus}

\section{INTRODUCTION}

In recent decades, dengue fever (DF) has been the most common mosquito-borne disease in tropical and sub-tropical regions of the world (Guzman M G, et al., 2014). The etiologic agent, dengue virus (DENV), belongs to the Flaviviridae family. It has four closely related serotypes (DENV-1-4). DENV infection can cause non-specific self-limited DF or severe fatal dengue hemorrhagic fever/dengue shock syndrome (DHF/DSS) (Bäck A T, et al., 2013; Halstead S B, 2012; Normile D, 2013). The incidence of DENV infection has increased 30 -fold over the last 50 years. In 2013, the annual global incidence, estimated by the World Health Organization (WHO), was close to 390 million and three times higher than that in 2009 (Bhatt S, et al., 2013; Normile D, 2013). Notably, three epidemics have emerged in southern Asia, southeast Asia, and the United States (Thomas S J, et al., 2011). Thus, as one of the fastest-spreading diseases worldwide, DENV infection is considered an important public health concern and a global epidemic by the WHO.

Dengue vaccines have been under development since

Received: 13 November 2014, Accepted: 16 December 2014 Published online: 24 December 2014

$\triangle$ Correspondence:

Hui Chen, +86-10-83911834, Email: chenhuicxh@ccmu.edu.cn; Jing An, +86-10-83950107, Email: anjing@ccmu.edu.cn the 1940s (Mahoney R, et al., 2011). However, there is still no licensed vaccine against DENV infection due to several reasons, particularly antibody-dependent enhancement (ADE). Because DENV has four distinct serotypes, there are cross immune responses among the serotypes. When humans are infected with one subtype of DENV or use a vaccine against one subtype DENV infection, they produce specific antibodies to that subtype. A secondary infection caused by a heterotypic serotype would induce more acute DHF/DSS. This phenomenon is called $\mathrm{ADE}$ and can increase the risk of severe dengue, including DHF/DSS, on a second heterologous infection (Wahala M P B, et al., 2011). As a result, antibodies can be beneficial or harmful, making DENV infection complex. To overcome this problem, when designing vaccines, a balance among antibody responses to all four serotypes should be considered. An effective DENV vaccine must achieve long-term protection against all four DENV serotypes; i.e., it must be tetravalent (Halstead S B, et al., 2005; Letson G W, et al., 2010; Simmons C P, et al., 2007). Additionally, although DENV can infect several nonhuman species, it does not cause disease or reproduce well in those species. Thus, there are no suitable animal models for vaccine evaluation. Beyond the inherent difficulty of vaccine development, additional challenges include knowledge of herd protection and vaccine efficacy in different areas of the world, limited understanding of heterologous immunity, and cost of 
vaccine delivery in developing countries (Letson $\mathrm{G} \mathrm{W}$, et al., 2010; Normile D, 2013; Thomas S J, 2011; Voelker R, 2010).

In recent years, there has been a rapid increase in knowledge of the molecular biology of DENV. The DENV genome, which is approximately $11 \mathrm{~kb}$ in length, has a single known open reading frame (ORF) encoding three structural proteins (capsid (C), pre-membrane (PrM), and envelope (E)) and seven non-structural proteins (NS1, NS2a, NS2b, NS3, NS4a, NS4b, and NS5) (Guzman M G, et al., 2014; Guzman M G, et al., 2010; Thomas S J, et al., 2011). Glycosylated E plays a dominant role in antibody generation. Correct folding of the E protein requires co-synthesis with PrM, which is cleaved to form the $\mathrm{M}$ protein during virion maturation. However, in certain instances, PrM cleavage is incomplete, allowing PrM to function as an additional protein for antibody induction. NS1 can trigger a protective response through an antibody-dependent complement-mediated pathway (Rothman A L, 2011). Therefore, E, PrM, and NS1 are the main molecular targets for the development of vaccines. By incorporating molecular knowledge of DENVs, virologists have made concerted efforts to develop several types of candidate DENV vaccines, including live attenuated vaccines (LAVs), inactivated vaccines, protein/subunit vaccines, DNA vaccines, and others (Rodriguez-Roche R, et al., 2013; Thisyakorn U, et al., 2014; Wan S W, et al., 2013). Although no dengue vaccine is currently licensed, significant progress has been made in the development of a vaccine, and several candidates are currently being evaluated in clinical studies. This review summarizes recent advances in vaccine development and provides new insight into future possibilities.

\section{LIVE ATTENUATED VACCINES}

The development of live attenuated tetravalent dengue vaccines is considered the most promising strategy against DENV infection. A number of these vaccines have advanced to clinical trials. Here several are summarized.

\section{DENVax}

Inviragen's tetravalent live attenuated dengue vaccine (DENVax), developed by researchers at the Division of Vector-borne Diseases of the Centers for Disease Control and prevention (CDC), is based on the backbone of the attenuated DENV-2 virus strain PDK-53, obtained by serial passage of wild-type viruses in primary dog kidney (PDK) cells (Bhamarapravati N, et al., 1987; Huang C Y, et al., 2003; Sabchareon A, et al., 2002). Vaccines for the remaining three serotypes were engineered by replacing the prM and E genes of an attenuated DENV-
2 strain with those of wild-type DENV-1 16007, DENV3 16562, and DENV-4 1036 (Huang C Y, et al., 2003; Sabchareon A, et al., 2002). Chimeric DENV-2/1, DENV-2/3, and DENV-2/4 replicated efficiently in Vero cells and were immunogenic in AG129 mice. These four DENVax components were formulated as a tetravalent chimeric dengue vaccine. The vaccine was tested for safety, immunogenicity, and efficacy in non-human primates. After subcutaneous vaccination with DENVax, no clinical signs of the disease were observed. In addition, strong $\mathrm{T}$ cell-mediated responses and robust production of IL- 2 and IFN- $\gamma$ were induced. As low viral titers were induced by this vaccine, it would be unlikely to infect feeding mosquitoes. Accordingly, it was unlikely to lead to unintended transmission. When tested in human volunteers, however, the antibodies were imbalanced for the four dengue serotypes following one or more inoculations. DENVax also gave poor protection against DENV3. However, there were no vaccination-related severe adverse events (AEs). This strategy could induce an antibody response against all dengue serotypes. However, dengue-like syndrome development, balancing attenuation to produce acceptable tetravalent immunogenicity with minimal reactogenicity, subjects' age, and ethical issues are all needed to be considered in future clinical trials (Kitchener S, et al., 2006; Sanchez V, et al., 2006). Fortunately, researchers recognize the importance of master virus seeds (MVS) and have begun to use this to improve DENVax. Recently, it has been evaluated in phase $1 \mathrm{~b}$ and 2 clinical trials. With clinical trials ongoing, DENVax might yet prove to be a safe and efficacious vaccine (Huang C Y, et al., 2013; Osorio J E, et al., 2011). Overall, DENVax proves that the DENV-2 PDK53 strain is an attractive vector for developing live attenuated vaccines. The DENVax has potential for phase $2 b / 3$ efficacy studies.

\section{3' UTR $\Delta 30 /$ vaccines}

The Laboratory of Infectious Diseases (LID) at the National Institutes of Allergy and Infectious Diseases (NIAID), a division of the National Institutes of Health $(\mathrm{NIH})$, has been developing a live attenuated tetravalent dengue vaccine for more than a decade (Durbin A P, et al., 2011).

The 3' untranslated region (UTR) of the flavivirus genome is considered critical to viral RNA replication. As a result, this region was selected for investigation. These researchers first built attenuated monovalent vaccines for each dengue serotype and then tried to mix the monovalent vaccines into a tetravalent vaccine that could induce a balanced immune response. They used a mutant with a 30-nucleotide deletion at positions 172-143 in the $3^{\prime}$ UTR of DENV-4, designated rDEN4 $\Delta 30$ (Durbin A P, et al., 2001; Men R, et al., 1996). At a dose of $10^{5} \mathrm{PFU}$, it was 
safe and immunogenic in both non-human primates and healthy volunteers. This strain proved attenuated enough to elicit protective antibody responses against the wildtype (wt) virus without apparent severe AEs. It was also safe enough to avoid transmission to mosquitoes. However, there were still some problems. Asymptomatic maculopapular rash, neutropenia and a temporary mild elevation of serum alanine amino transferase (ALT) levels were the most common AEs. To determine whether these AEs were dose-related, three doses were evaluated further: $10^{3}, 10^{2}$, and $10^{1} \mathrm{PFU}$. The investigators also hoped to determine the dose giving $50 \%$ human infection $\left(\mathrm{HID}_{50}\right)$ in this study. At these reduced doses, the incidence of serum ALT elevation (1/60) was significantly lower than at $10^{5} \mathrm{PFU}(5 / 20)$. However, the frequency of rash and neutropenia was not affected. In regards to the $\mathrm{HID}_{50}$, researchers found that a dose of $10^{3} \mathrm{PFU}$ induced protective antibodies (58/60) with fewer AEs. For this reason, they used this dose for further evaluation of this and other serotype vaccines (Durbin A P, et al., 2005; Durbin A P, et al., 2001; Hanley K A, et al., 2002).

To reduce the hepatotoxicity of $\operatorname{rDENV} 4 \Delta 30$, two additional recombinant DENV-4 vaccines were further attenuated from rDENV $4 \Delta 30$, and each was named rDENV4 $\Delta 30-200,201$ and rDENV4 $\Delta 30-4995$. They also underwent other changes. The former encodes two charge-to-alanine substitutions at amino acid residues 200 and 201 in the NS5 protein, and the latter encodes a single residue mutated at amino acid 158 of NS3 (McArthur J H, et al., 2008; Wright P F, et al., 2009). In clinical trials, rDEN4 $\Delta 30-4995$ was abandoned due to poor immunogenicity, but rDENV4 $\Delta 30-200$, 201 had a lower incidence of rash and ALT elevation than rDEN4 $\Delta 30$. Therefore, rDENV4 30 and rDENV4 $\Delta 30-200,201$ are currently being evaluated as components of a tetravalent LAV.

Studies have shown that the 3'UTR contains several stem loop structures that are conserved in DENV (Brinton M A, et al., 1986). One of these stem loop structures, TL2, was used to develop rDENV4 430 (deletion of 3 ' nucleotides 172-143). TL2 was also used to design $\mathrm{rDENV} 1 \Delta 30, \mathrm{rDENV} 2 \Delta 30$, and $\mathrm{rDENV} 3 \Delta 30$. Of these, rDENV1 $\triangle 30$, based on DENV-1 Western Pacific (WP) strain, has been evaluated in clinical trials. In animal experiments, it was safe, induced significant antibody production, and avoided infection with wt DENV-1. In volunteers, a single dose of $10^{3}$ PFU was optimal, being effective for more than 6 months. AEs were similar to rDENV4 $\triangle 30$ including rash, neutropenia and ALT elevation (Halstead S B, et al., 2011; Whitehead S S, et al., 2003). Above all, rDENV1 $\Delta 30$ was safe and immunogenic enough for further evaluation.

Unfortunately, researchers confronted difficulties when building monovalent vaccines for DENV-2 and
DENV-3, and rDENV $2 \Delta 30$ and $\operatorname{rDENV} 3 \Delta 30$ were not successful. They found that rDEN2 $\Delta 30$ was not fully attenuated and that $\mathrm{rDEN} 3 \Delta 30$ did not prevent viral replication in animals (Blaney J E, et al., 2004a; Blaney J E, et al., 2004b). To solve this problem, they created chimeras from two different serotypes of DENV, giving rDEN$\mathrm{V} 2 / 4 \Delta 30(\mathrm{ME})$ and $\mathrm{rDENV} 3 / 4 \Delta 30(\mathrm{ME})$. In clinical trials, rDENV2/4 $\triangle 30(\mathrm{ME})$ proved suitable for further evaluation in tetravalent LAV (Durbin A P, et al., 2006; Whitehead S $\mathrm{S}$, et al., 2003). However, rDENV3/4 $\Delta 30$ (ME) had disappointing immunogenicity even at $10^{5} \mathrm{PFU}$. Consequently, using recombinant DNA technology, two further alternative strategies, rDENV3-3'D4 $\Delta 30$ and $\operatorname{rDENV} 3 \Delta 30 / 31$, were devised. Both vaccines showed favorable results in clinical trials, suitable for further evaluation as components of tetravalent LAV (Blaney J E, et al., 2008).

When administered to humans, researchers still do not know the immunogenicity of the tetravalent LAV formulated from several monovalent vaccines. They hope to develop a better understanding of the monovalent interference with one another in tetravalent vaccines and to develop a safe, immunogenic, and protective tetravalent LAV.

\section{Sanofi Pasteur CYD tetravalent dengue vaccine (TDV)}

The first generation of LAV dengue vaccines, developed by serial cell passage, had several flaws. Of primary concern was that they were genetically and phenotypically unstable and caused AEs. To overcome these problems, the second-generation vaccine CYD-TDV was developed in the early 2000's by Acambis (now Sanofi Pasteur) (Lang J, 2012). CYD-TDV is composed of four live attenuated virus strains (CYD-1-4). Each was based on a yellow fever virus 17D (YFV 17D) vaccine backbone, replacing the genes encoding the PrM and E proteins from YFV 17D with those from DENV. Monovalent serotype 1, 2, 3, and 4 CYD viruses (CYD-1, 2, 3 and 4) express the pre-membrane and envelope genes of the corresponding DENV serotype. These CYD monovalents were combined as a single vaccine preparation (TDV) (Guy B, et al., 2010; Guy B, et al., 2011; Lang J, 2012). Before clinical trials, all vaccine candidates were tested for safety and immunogenicity. Extensive pre-clinical research revealed that these vaccine candidates were genotypically and phenotypically stable and unlikely to revert to virulence or to recombine with other flaviviruses. Moreover, the likelihood of CYD viruses spreading via mosquitoes is low. In non-human primates, TDV was defined as $5 \log _{10} \mathrm{CCID}_{50}$ of each virus (5555 formulation) (Guy B, et al., 2009). CYD-2 was evaluated in phase I clinical trials in US adults for safety profile determination (Guirakhoo F, et al., 2006). Subsequent phase I clinical evaluations in Mexico and the Philippines 
were carried out at 3 doses administered at $0,3.5$ and 12 months, or 2 doses 8-9 months apart (Capeding R Z, et al., 2011; Poo J, et al., 2011). These studies were performed in people aged $2-45$ years, with various flavivirus preimmune statuses. A satisfactory safety profile and low levels of viremia were observed after vaccination. After the first administration, the humoral response was predominantly against serotype 4 . The second or third doses then balanced the immune response across all four serotypes. Preimmunity against flavivirus had a positive impact and caused little negative effect on safety. Cellular immune responses were also tested, giving a favorable safety profile (Guy B, et al., 2008). Based on the phase I clinical evaluation, CYD-TDV was given in 3 doses at 0 , 6, and 12 months. Geometric mean titers (GMTs) for all serotypes were better under this regimen than the former schedule ( 3 doses at $0,3.5$, and 12 months).

Phase II trials were conducted in a larger population, including children, adolescents and adults, with different flavivirus infection and vaccination histories (Harenberg A, et al., 2013; Leo Y S, et al., 2012; Sabchareon A, et al., 11 September 2012). Co-administration with another live virus vaccine (measles, mumps and rubella vaccine) was also considered to evaluate safety and immunogenicity. In parallel with these phase II safety and immunogenicity studies, CYD-TDV was the first dengue vaccine to enter phase III clinical trials, starting in Australia in 2010. The first efficacy study included 4,000 children (4-11 years) from the highly endemic area of Thailand. To compare the efficacy of CYD-TDV in different countries, phase III trials were also carried out in Asia (Thailand, Indonesia, Malaysia, Viet Nan and Philippines) and included approximately 10,000 children (2-14 years). In Latin America (Colombia, Mexico, Honduras, Porto Rico and Brazil) approximately 20,000 children aged 9-16 years were enrolled (Guy B, et al., 2011; Lang J, 2012). In early evaluations, CYD-TDV had genetic and phenotypic stability and a low likelihood of spreading via mosquitoes. CYD-TDV induced both humoral and cellular responses, few severe AEs, and only mild viremia, indicating a bright future.

However, by the end of phase IIb trials in Thailand, this TDV demonstrated poor efficacy against DENV-2, despite satisfactory PRNT titers (Sabchareon A, et al., 11 September 2012). As of January 2013, more than 28,900 individuals have received one or more CYDTDV vaccinations, with no safety signals identified. In Singapore, scientists found that the immune response to CYD-TDV was stronger in children and adults than in adolescents (Harenberg A, et al., 2013). This difference was also observed in both females and males. During this study, severe AEs were observed. Owing to these issues, the development of CYD-TDV was ended in 2012 (Normile D, 2013). More recently, the CYD-TDV study group reported new results of CYD-TDV in a phase III trial ended in 2014, and they demonstrated that the dengue vaccine was efficacious against virologically confirmed dengue (VCD) and severe VCD, and led to fewer hospitalizations for VCD in five Latin American countries where dengue is endemic (Villar L, et al., 2014).

\section{WRAIR/GSK tetravalent passaged live attenuated vaccine}

The Walter Reed Army Institute of Research (WRAIR) and GlaxoSmithKline Biologicals (GSK) have been co-developing live tetravalent dengue vaccines for some time. These vaccine candidates, comprising four monovalent live virus strains, are now being evaluated in phase II for safety and immunogenicity (Sun W, et al., 2009; Thomas S J, et al., 2013). In the 1970s, Halstead (University of Hawaii) discovered that DENV could be propagated serially in primary dog kidney (PDK) cells. (Halstead S B, 1978) These seed viruses were sent to the WRAIR for further study. WRAIR set out to develop a cloned, temperature-sensitive, live attenuated vaccine candidate for each DENV serotype. They used PDK passage to reduce infectivity. Ten monovalent candidates were obtained. Three attenuated strains were tested for DENV-1 and DENV-2, and two were tested each for DENV-3 and DENV-4 (Innis B L, et al., 2003). Expanded studies were carried out to evaluate a tetravalent vaccine candidate comprising four serotypes of live attenuated DENV (Anderson K B, et al., 2011). After a series of preclinical and phase I/II trials, it was found that the tetravalent vaccine was safe and well tolerated, eliciting immune responses against all four DENV serotypes. However, antibody production was not fully correlated with protection, and antibody responses to DENV-3 and DENV-4 were not satisfactory (Sun W, et al., 2006). Although no severe AEs were associated with the TDV, mild to moderate redness at the injection site was frequently observed after vaccination. Other AEs included elevated temperature (most often after dose 2), rash, and transient increases in AST (up to $648 \mathrm{U} / \mathrm{L}$ ) and ALT (up to $566 \mathrm{U} / \mathrm{L}$ ). Seven of the 34 subjects who received TDV were viremic on day 10 post-vaccination, with DENV$4(\mathrm{~N}=5)$ or DENV-2 $(\mathrm{N}=2)$ viremia (Watanaveeradej $\mathrm{V}$, et al., 2011). Based on these preliminary results, two DENV-1 candidates (West Pac 74, 45AZ5, PDK-27) were acceptable. A single vaccine was finally selected for the other three DENV serotypes: DENV-2 (S16803, PDK-50), DENV-3 (H53489, PDK-20), and DENV-4 (341750, PDK-6) (Sun W, et al., 2009; Thomas S J, et al., 2013). For better attenuation, these monovalent vaccine candidates underwent three additional passages in fetal rhesus lung $(\mathrm{FRhL})$ cells and were formulated with a carbohydrate stabilizer instead of human serum albumin. 
The final vaccine was lyophilized as a tetravalent product. Two formulations of TDV (F17 and F19) were evaluated in a randomized, observer-blind phase II trial in 86 healthy adults. AEs included headache (33.3\%-54.5\% after dose 1 and $16.7 \%-37.5 \%$ after dose 2 ) and fatigue (22.7\%-36.4\% after dose 1 and $15 \%-25 \%$ after dose 2$)$. Fewer AEs were observed after dose 3 . After two doses, no DENV-1, -2 , or -3 related viremia was detected 31 days post-vaccination, except for one subject $(5.3 \%)$ in the F17 group between days 5 and 14 post-vaccination. DENV-4 viremia ranged from 4.6-5.2 log Geq/mL. Seroconversion for TDV F17 was $37.5 \%$ after dose 1 and $60.0 \%$ after dose $2 ; \mathrm{F} 19$ yielded $40.0 \%$ after dose 1 and $66.7 \%$ after dose 2 . A third dose administered 5-12 months after the second was ineffective in boosting immune responses to the four DENV serotypes (Thomas S J, et al., 2013). These two TDV formulations are now being evaluated in a larger number of subjects.

\section{Novel recombinant protein/subunit vaccines}

Re-combinant DENV protein/subunit vaccines expressed in different systems have been evaluated as alternative strategies. Compared to live attenuated vaccines, recombinant protein/subunit vaccines are safer and more readily manipulated through dose adjustment, allowing a balanced immune response to all four DENV serotypes. However, this strategy has the problem of incomplete post-translational processing of proteins, which might differ from native proteins and therefore induce unwanted immune responses. Together with other obstacles such as poor immunogenicity, multi-dose vaccination and the need for adjuvants to generate sufficient immune response, the development of recombinant protein/subunit vaccines is challenging (Thisyakorn U, et al., 2014; Wan S W, et al., 2013). Those currently under investigation will be described briefly in the following sections.

\section{PD5 and Domain III-capsid (DIIIC) protein vaccine}

Researchers at the Center for Genetic Engineering and Biotechnology (CIGB) in Cuba have designed two novel recombinant protein vaccines. One is recombinant protein PD5, which contains domain III coding for amino acids 286-426 of the E protein from DENV-2, fused to the carrier protein P64k. Serogroup A capsular polysaccharide (CPS-A) from $N$. meningitis and aluminum hydroxide are used as adjuvants. Preclinical trials in monkeys demonstrated that the PD5 vaccine (or PD5CPS-A) induced humoral and cell-mediated immune responses after four doses. Antibodies were still detected at day 420 (Valdés I, et al., 2009a). In a follow-up experiment, animals were infected with DENV-2, then received the PD5-CPS-A vaccine 5 months later. This revealed that the recombinant protein PD5 could recall immune responses. Thus, the PD5 vaccine was tested further in combination with attenuated virus vaccines (Valdés I, et al., 2010).

Recognizing the protective capacity of the DENV capsid antigen, researchers designed another recombinant protein vaccine as an alternative: the domain III capsid. Like PD5, it was tested in monkeys for heterologous boosting, as either a prime or a boost dose. Initially there were two different formulations of this candidate: aggregated (mixed with oligodeoxynucleotides) and non-aggregated. In preclinical tests, these two candidates induced similar humoral responses, but the aggregated formulation resulted in stronger cell-mediated immunity. In another trial, the aggregated formulation was also able to boost antibodies. Accordingly, it was evaluated further (Valdés I, et al., 2009b; Valdes I, et al., 2011).

Although these two vaccine candidates (PD5 and domain III-capsid) are effective against only DENV-2 in their current iterations, additional development would be worthwhile to promote immunity against other DENV serotypes.

\section{$80 E$ subunit vaccine candidate}

Hawaii Biotech and the WRAIR have developed a tetravalent vaccine candidate by combining the truncated envelope protein subunits (80E) from each of the four dengue serotypes with ISCOMATRIX ${ }^{\mathrm{TM}}$ adjuvant (Clements D E, et al., 2010). The monovalent subunit was expressed in the Drosophila melanogaster S2 cell line originally developed by SmithKline Beecham (Van der Straten A, et al., 1989). Using this system, it was possible to overcome limitations in protein expression. Briefly, 80Es truncated at amino acid 395 (DENV-1, -2, and -4) or 393 (DENV-3) were inserted into the pMtt $\Delta$ Xho vector and then into S2 cells, to obtain stable cell lines. The dengue $80 \mathrm{E}$ proteins had high expression levels and maintained a native-like conformation (Coller B A G, et al., 2011). In preclinical trials, these four $80 \mathrm{E}$ proteins were tested with different adjuvants (Garçon N, et al., 2011; McKeage K, et al., 2011; McKenzie A, et al., 2010). The durability of the immune response was also tested for DENV-2 80E formulated with several adjuvants. DENV-2 $80 \mathrm{E}$ formulated with ISCOMATRIX $^{\mathrm{TM}}$ adjuvant persisted for at least 6 months and induced the best memory component. Finally, $80 \mathrm{E}$ proteins formulated with ISCOMATRIX ${ }^{\mathrm{TM}}$ adjuvant gave satisfactory results in both mice and non-human primates (Clements D E, et al., 2010).

To develop a tetravalent dengue vaccine, these four dengue $80 \mathrm{E}$ proteins were mixed together in equal amounts and formulated with ISCOMATRIX ${ }^{\mathrm{TM}}$ adjuvant. In mice, the antibody titers induced by this tetravalent candidate were similar to those induced by the monovalent candidates. A balanced tetravalent immune response 
was observed in animals vaccinated with tetravalent $80 \mathrm{E}$. A further experiment was undertaken to evaluate the immunogenicity and protective efficacy of this tetravalent vaccine candidate in monkeys. Each monkey received 4 doses at $0,1,2$, and 3 months. It was found that both low and moderate doses were well tolerated, without any AEs. Moreover, protective immunity was observed against more than one dengue serotype. These results identified dengue $80 \mathrm{E}$ proteins as safe, effective and affordable vaccine candidates and they have now advanced to phase I clinical trials (Coller B A G, et al., 2011).

\section{Inactivated dengue vaccine}

It is more than 70 years since researchers first attempted to develop inactivated DENV vaccines (Durbin A P, et al., 2010). Although in other areas, especially in the prevention of Japanese encephalitis virus (JEV), this type of vaccine strategy has been successful, inactivated vaccines against DENV are still under development (Aihara $\mathrm{H}$, et al., 2000).

Inactivated DENV vaccines have unique advantages over other vaccine construction methods. They are unlikely to revert to a more pathogenic phenotype. They are also unlikely to interfere with each other (different serotypes of inactivated DENV) when combined. Moreover, inactivated viruses can even be administered to immunocompromised individuals. Obviously, they have shortcomings as well. Inactivated DENV vaccines require multiple injections. In addition, production is costly. In developing inactivated DENV vaccines, the adjuvant plays a crucial role. Therefore, finding the ideal adjuvant is critical (Durbin A P, et al., 2010; Robert Putnak J, et al., 2005; Thisyakorn U, et al., 2014).

A tetravalent purified inactivated DENV-2 vaccine (DPIV) is being explored by the Killed Dengue Vaccine Initiative from WRAIR, GSK, and the Oswald Cruz Foundation. Briefly, the vaccine candidate was developed in Vero cells harvested from roller bottle culture supernatant. After purification, it was inactivated with $0.05 \%$ formalin at $22{ }^{\circ} \mathrm{C}$ (Putnak R, et al., 1996). After evaluation in animals for several years, this DPIV was found to produce anti-DENV antibodies with few AEs. However, based on limited results, one obvious problem was incomplete protection (Robert Putnak J, et al., 2005). Another problem impeding the development of the PIV was that existing adjuvants did not increase immunogenicity. Currently this DPIV has been combined with other adjuvants and has progressed to phase I trials (Garçon N, et al., 2011; Morel S, et al., 2011; Thisyakorn U, et al., 2014).

\section{DNA VACCINES}

The concept of DNA vaccination can be traced back to the $1990 \mathrm{~s}$, immediately gaining wide recognition due to its many advantages. In general, DNA vaccines are composed of a plasmid or plasmids containing dengue target genes that can be expressed in vivo persistently and induce both humoral and cellular immune responses. DNA vaccines are easy to produce and relatively stable at room temperature. They also have low reactionogenicity and cost. Despite the theoretical risk of nucleic acid integration into the host's DNA or induction of anti-DNA antibodies, it appears unlikely to happen in practice (Beckett C G, et al., 2011; Sardesai N Y, et al., 2011).

\section{DENV-1 DNA vaccine (D1ME ${ }^{100}$ )}

A DENV-1 DNA vaccine was developed in the Naval Medical Research Center, United States. The DENV1 vaccine construct $\left(\mathrm{D} 1 \mathrm{ME}^{100}\right)$, using plasmid vector VR1012, expresses the PrM and E genes of DENV-1. When tested in rhesus macaques and Aotus monkeys, it provided $80 \%-95 \%$ protection against live virus challenge (Raviprakash K, et al., 2000). To evaluate safety and immunogenicity in flavivirus-negative volunteers, it was administered in 3 doses at 0,1 , and 5 months. None of the 10 volunteers receiving a low dose $(1.0 \mathrm{mg})$, but 5 of $12(41.6 \%)$ subjects receiving a high dose $(5.0 \mathrm{mg})$ developed neutralizing antibodies. The IFN-g responses were $50 \%(4 / 8)$ and $83 \%(10 / 12)$ in the low and high dose groups, respectively. Although the cross-reactive $\mathrm{T}$ cell responses were lower overall than the serotype-specific responses, they did occur after administration with D1ME ${ }^{100}$. Common AEs were mild local pain or tenderness $(10 / 22,45 \%)$, mild swelling at the vaccination site $(6 / 22,27 \%)$, muscle pain $(6 / 22,27 \%)$ and fatigue $(6 / 22$, $27 \%$ ). No severe AEs were observed (Beckett C G, et al., 2011). Overall, the candidate gave favorable results and further studies are been carried out.

\section{Tetravalent DNA vaccine (WRAIR)}

The Naval Medical Research Center and Walter Reed Army Institute of Research are using a new strategy to evaluate their tetravalent DNA vaccine. Flavivirus-naïve rhesus macaques were primed with tetravalent plasmid DNA vaccines (TDNA) and then boosted with TLAV two months later. Neutralizing antibody titers and viremia were observed after challenge with a near-wildtype strain of DENV-3 (Simmons M, et al., 2010). Each monovalent vaccine candidate contained the DENV PrM, full-length $\mathrm{E}$ genes, and was cloned into plasmid vector pVR1012. Animals received $5 \mathrm{mg}$ (1.25 mg/serotype) of TDNA vaccine per dose, administered intramuscularly in the upper arm. After challenge with DENV-3 at month 8, antibody GMTs to all DENV serotypes increased in all vaccine groups. Compared with the control group, the neutralizing titers to DENV-3 were 50 -fold higher. Although viremia in the experimental group was shorter 
(1.5 days on average) than in the control group (5 days), the TDNA/TLAV strategy did not provide complete protection against DENV. Elucidation of the reasons for the failure of high antibody titers to provide full protection requires further study. Overall, this work gives us a novel strategy to evaluate DENV vaccines.

Additionally, monovalent DNA vaccine construction has been developed by a research group in Beijing China, with pCAGGSP7 (pCAG) and internal ribosome entry site (IRES) used to express DENV antigens of
prM-E or prM-E-NS1. These vaccine candidates were tested in mice and the results revealed that DNA vaccines expressing antigens of DENV-1 or DENV-2 could produce good humoral immune responses, strong CTL activity and protective efficiency. The protection rates in immunized mice ranged from $30 \%-100 \%$ after challenging with DENV-1 or DENV-2 (Lu H, et al., 2013; Zheng Q, et al., 2011). Now, these strategies have been tested in mice for other DENV serotypes using a new delivery method (Lu H, et al., 2013; Zheng Q, et al., 2011).

Table 1. Dengue vaccines in clinical development*

\begin{tabular}{|c|c|c|}
\hline Developer & Product description & Stage \\
\hline Takeda Pharmaceuticals / Inviragen & $\begin{array}{l}\text { Live attenuated DNA tetravalent vaccine (attenuated DEN2 } \\
\text { PDK-53 virus and DEN/DEN intertypic chimeric viruses) }\end{array}$ & Phase 2 \\
\hline $\begin{array}{l}\text { National Institutes of Allergy and } \\
\text { Infectious Diseases/ Butantan Institute }\end{array}$ & $\begin{array}{l}\text { Live attenuated vaccine (targeted mutagenesis of DEN } \\
\text { viruses and DEN/DEN intertypic chimeric virus) }\end{array}$ & Phase 2 \\
\hline Sanofi Pasteur & $\begin{array}{l}\text { ChimericVax-Dengue. Live attenuated tetravalent vaccine } \\
\text { (Yellow Fever 17D/DEN chimeric viruses) }\end{array}$ & Phase 3 \\
\hline $\begin{array}{l}\text { The Walter Reed Army Institute of } \\
\text { Research and GlaxoSmithKline } \\
\text { Biologicals }\end{array}$ & $\begin{array}{l}\text { Live attenuated DNA tetravalent vaccine attenuated in } \\
\text { PDK-53 cells and fetal rhesus lung (FRhL) cells) }\end{array}$ & Phase 2 \\
\hline $\begin{array}{l}\text { Center for Genetic Engineering and } \\
\text { Biotechnology }\end{array}$ & $\begin{array}{l}\text { Recombinant protein PD5 (domain III of the envelope E } \\
\text { protein from DENV-2 fused to the protein carrier p64k)/ } \\
\text { Recombinant domain III-capsid protein (comprises the } \\
\text { domain III region of the envelope protein and the capsid } \\
\text { protein, both from DENV-2) }\end{array}$ & Preclinical trials \\
\hline Merck/Hawaii Biotech & $\begin{array}{l}\text { Recombinant DEN1-80E subunit protein vaccine (truncated } \\
\text { E version) }\end{array}$ & Phase 1 \\
\hline $\begin{array}{l}\text { GlaxoSmithKline/Oswaldo Cruz } \\
\text { Foundation/Walter Reed Army Institute } \\
\text { of Research }\end{array}$ & DEN1, purified inactivated virus vaccine & Phase 1 \\
\hline $\begin{array}{l}\text { Naval Medical Research Center, Viral } \\
\text { \& Rickettsial Diseases Department }\end{array}$ & $\begin{array}{l}\text { Developed by incorporating pre-membrane and envelope } \\
\text { genes into a plasmid vector and expresses the prM and } E \\
\text { genes of DENV-1 }\end{array}$ & Phase 1 \\
\hline $\begin{array}{l}\text { The Naval Medical Research Center } \\
\text { and Walter Reed Army Institute of } \\
\text { Research }\end{array}$ & $\begin{array}{l}\text { Priming with tetravalent purified inactivated virus (TPIV) } \\
\text { expressing the structural prM/E gene region (TDNA) then } \\
\text { boosting with a tetravalent live attenuated virus (TLAV) } \\
\text { vaccine }\end{array}$ & Preclinical trials \\
\hline $\begin{array}{l}\text { Department of Microbiology, School } \\
\text { of Basic Medical Sciences, Capital } \\
\text { Medical University }\end{array}$ & $\begin{array}{l}\text { Developed recombinant plasmid (pCAGGSP7 and internal } \\
\text { ribosome entry site (IRES)) expressing DENV antigens of } \\
\text { prM-E or prM-E-NS1 of DENV }\end{array}$ & Preclinical trials \\
\hline $\begin{array}{l}\text { International Centre for Genetic } \\
\text { Engineering and Biotechnology, New } \\
\text { Delhi, India }\end{array}$ & $\begin{array}{l}\text { Based on DENV-2 E protein VLPs developing virus-vectored } \\
\text { DENV vaccine }\end{array}$ & Preclinical trials \\
\hline
\end{tabular}

*Adapted from references (Arora U, et al., 2013; Beckett C G, et al., 2011; Lu H, et al., 2013; Simmons M, et al., 2010; Sinha G, 2014; Thomas S J, et al., 2013; Valdés I, et al., 2010; Valdes I, et al., 2011) 


\section{VIRUS-VECTORED DENV VACCINES}

Virus-like particles (VLPs) can elicit robust immunity in the absence of infection. These foreign proteins, expressed by recombinant poxviruses and adenoviruses, cause strong humoral and cellular responses in humans against various pathogens (Durbin A P, et al., 2010; Thisyakorn U, et al., 2014). Despite limited success to date, several virus vectors such as adeno-, alpha-, and vaccinia viruses are being used to develop dengue vaccine candidates (Thisyakorn U, et al., 2014).

Researchers at the International Centre for Genetic Engineering and Biotechnology, New Delhi, India have developed a virus-vectored DENV vaccine based on DENV-2 E protein VLPs expressed in the methylotrophic yeast Pichia pastoris. This vaccine candidate encodes the N-terminal 395 amino acid residues of the DENV-2 E protein. It also contains part of the 5' pre-membrane-derived signal peptide-encoding sequences, to achieve proper translational processing (Mani S, et al., 2013). It can be expressed at high levels in several strains of mice with satisfactory immunogenicity. High antibody titers were also elicited (Upasana Arora, et al., 2013). This candidate is under further evaluation. If necessary, multivalent VLPs could be constructed. Moreover, recombinant E proteins expressed in yeast and insect cells and VLPbased dengue vaccines have been evaluated in preclinical trials elsewhere (Thisyakorn U, et al., 2014).

\section{CONCLUSION}

Dengue outbreaks have become a serious public health concern worldwide. Currently there is still no specific drug against DENV, and vector control has achieved limited success. Therefore, vaccine development has become more important to prevent damage caused by DENV. For a candidate dengue vaccine to be successful, it must exhibit good immunogenicity and protective efficacy. It should not cause $\mathrm{ADE}$ and should show no cross-reactivity with host proteins (Mahoney R, et al., 2011; Wahala M. P. B., et al., 2011). Although the new emerging DENV-5 is slowing the progress of vaccine development, advancements are still being made and several candidate dengue vaccines are under development (Table 1), in particular Sanofi's dengue vaccine, which was the first to complete phase III testing (Normile D, 2013; Sinha G, 2014). Several vaccines have been evaluated in clinical, preclinical and animal trials (RodriguezRoche R, et al., 2013; Thisyakorn U, et al., 2014; Wan $\mathrm{S}-\mathrm{W}$, et al., 2013). It is wise to comprehensively assess each candidate. With recent technological advancements and continuing expansion of the knowledge of dengue infection molecular mechanisms, it is likely that a DENV vaccine will be licensed in the near future.

\section{ACKNOWLEDGMENTS}

This work was supported by grants from the National Natural Science Foundation of China (81372935, 81271839, 81401676 and 81301435).

\section{COMPLIANCE WITH ETHICS GUIDELINES}

All the authors declare that they have no competing interests. This article does not contain any studies with human or animals subjects performed by any of the authors.

\section{REFERENCES}

Aihara H, Takasaki T, Toyosaki-Maeda T, Suzuki R, Okuno Y, Kurane I. 2000. T-cell activation and induction of antibodies and memory $\mathrm{T}$ cells by immunization with inactivated Japanese encephalitis vaccine. Viral Immunol, 13: 179-186.

Anderson K B, Gibbons R V, Edelman R, Eckels K H, Putnak R J, Innis B L, W S. 2011. Interference and Facilitation Between Dengue Serotypes in a Tetravalent Live Dengue Virus Vaccine Candidate. J Infect Dis 204, 204: 442-450.

Arora U, Tyagi P, Swaminathan S, Khanna N. 2013. Virus-like particles displaying envelope domain III of dengue virus type 2 induce virus-specific antibody response in mice. Vaccine, 31 : 873-878.

Bäck A T, Lundkvist $\AA$. 2013. Dengue viruses - an overview. Infect Ecol Epidemiol, 3.

Beckett C G, Tjaden J, Burgess T, Danko J R, Tamminga C, Simmons M, Wu S-J, Sun P, Kochel T, Raviprakash K, Hayes C G, Porter K R. 2011. Evaluation of a prototype dengue-1 DNA vaccine in a Phase 1 clinical trial. Vaccine, 29: 960-968.

Bhamarapravati N, Yoksan S, Chayaniyayothin T, Angsubphakorn S, Bunyaratvej A. 1987. Immunization with a live attenuated dengue-2-virus candidate vaccine (16681-PDK 53): clinical, immunological and biological responses in adult volunteers. Bull World Health Organ, 65: 189-195.

Bhatt S, Gething P W, Brady O J, Messina J P, Farlow A W, Moyes C L, Drake J M, Brownstein J S, Hoen A G, Sankoh O, Myers M F, George D B, Jaenisch T, Wint G R W, Simmons C P, Scott T W, Farrar J J, Hay S I. 2013. The global distribution and burden of dengue. Nature, 496: 504-507.

Blaney J E, Hanson C T, Firestone C Y, Hanley K A, Whitehead S S. 2004a. Genetically modified, live attenuated dengue virus type 3 vaccine candidates. Am J Trop Med Hyg, 71: 811-821.

Blaney J E, Hanson C T, Hanley K A, Murphy B R, Whitehead S S. 2004b. Vaccine candidates derived from a novel infectious cDNA clone of an American genotype dengue virus type 2 . BMC Infect Dis, 4: 39.

Blaney J E, Sathe N S, Goddard L, Hanson C T, Romero T A, Hanley K A, Murphy B R, Whitehead S S. 2008. Dengue virus type 3 vaccine candidates generated by introduction of deletions in the 3'untranslated region (3'-UTR) or by exchange of the DENV-3 3'-UTR with that of DENV-4. Vaccine, 26: 817-828.

Brinton M A, Fernandez A V, Dispoto J H. 1986. The 3'-nucleotides of flavivirus genomic RNA form a conserved secondary structure. Virology, 153: 113-121.

Capeding R Z, Luna I A, Bomasang E, Lupisan S, Lang J. 2011. Liveattenuated, tetravalent dengue vaccine in children, adoles- 
cents and adults in a dengue endemic country: randomized controlled phase I trial in the Philippines. Vaccine, 29: 3863-3872.

Clements D E, Coller B A, Lieberman M M, Ogata S, Wang G, Harada K E. 2010. Development of a recombinant tetravalent dengue virus vaccine: immunogenicity and efficacy studies in mice and monkeys. Vaccine, 28: 2705-2715.

Coller B A G, Clements D E, Bett A J, Sagar S L, Meulen J H T. 2011. The development of recombinant subunit envelope-based vaccines to protect against dengue virus induced disease. Vaccine, 29: 7267-7275.

Durbin A P, Whitehead S S. 2010. Dengue Vaccine Candidates in Development. Curr Top Microbiol Immunol, 338:129-143.

Durbin A P, Kirkpatrick B D, Pierce K K, Schmidt A C, Whitehead S S. 2011. Development and clinical evaluation of multiple investigational monovalent DENV vaccines to identify components for inclusion in a live attenuated tetravalent DENV vaccine. Vaccine, 29: 7242-7250.

Durbin A P, Whitehead S S, McArthu r J, Perreault J R, Blaney J E, Thumar B. 2005. rDEN4 Delta 30, a Live Attenuated Dengue Virus Type 4 Vaccine Candidate, Is Safe, Immunogenic, and Highly Infectious in Healthy Adult Volunteers. J Infect Dis, 191: 710-718.

Durbin A P, McArthur J H, Marron J A, Blaney J E, Thumar B, Wanionek K. 2006. rDEN2/4Delta30(ME), A Live Attenuated Chimeric Dengue Serotype 2 Vaccine Is Safe and Highly Immunogenic in Healthy Dengue-Naive Adults. Hum Vaccin, 2: 255-260.

Durbin A P, Karron R A, Sun W, Vaughn D W, Reynolds M J, Murphy B R, Whitehead S S. 2001. Attenuation and immunogenicity in humans of a live dengue virus type- 4 vaccine candidate with a 30 nucleotide deletion in its 3'-untranslated region. Am J Trop Med Hyg, 65: 405-413.

Garçon N, Van Mechelen M. 2011. Recent clinical experience with vaccines using MPL- and QS-21-containing Adjuvant Systems. Expert Rev Vaccines, 10: 471-486.

Garçon N, Wettendorff M, Van Mechelen M. 2011. Role of AS04 in human papillomavirus vaccine: mode of action and clinical profile. Expert Opin Biol Ther, 11: 667-677.

Guirakhoo F, Kitchener S, Morrison D, Forrat R, McCarthy K, Nichols R, Yoksan S, Duan X, Ermak T H, Kanesa-thasan N, Bedford P, Lang J, Quentin-Millet M-J, Monath T P. 2006. Live attenuated chimeric yellow fever dengue type 2 (ChimeriVax-DEN2) vaccine: Phase I clinical trial for safety and immunogenicity: effect of yellow fever preimmunity in induction of cross neutralizing antibody responses to all 4 dengue serotypes. Hum Vaccin, 2: 60-67.

Guy B, Saville M, Lang J. 2010. Development of Sanofi Pasteur tetravalent dengue vaccine. Hum Vaccin, 6: 696-705.

Guy B, Nougarede N, Begue S, Sanchez V, Souag N, Carre M. 2008. Cellmediated immunity induced by chimeric tetravalent dengue vaccine in naive or flavivirus-primed subjects. Vaccine, 26: 12-21.

Guy B, Barrere B, Malinowski C, Saville M, Teyssou R, Lang J. 2011. From esearch to phase III: preclinical, industrial and clinical development of the Sanofi Pasteur tetravalent dengue vaccine. Vaccine, 29: 7229-7241.

Guy B, Barban V, Mantel N, Aguirre M, Gulia S, Dumas R, Lang J. 2009. Evaluation of Interferences between Dengue Vaccine Serotypes in a Monkey Model. Am J Trop Med Hyg, 80: 302-311.

Guzman M G, Harris E. 2014. Dengue. The Lancet, Epub ahead of print. doi: 10.1016/S0140-6736(14)60572-9.

Guzman M G, Halstead S B, Artsob H, Buchy P, Farrar J, Gubler D J, Hunsperger E, Kroeger A, Margolis H S, Martínez E, Nathan M B, Pelegrino J L, Simmons C, Yoksan S, Peeling R W. 2010. Dengue: a continuing global threat. Nat Rev Microbiol, 8:
S7-S16.

Halstead S B. 1978. Studies on the attenuation of dengue 4. Asian J Infect Dis, 2: 112-117.

Halstead S B. 2012. Controversies in dengue pathogenesis. Paediatr Int Child H, 32: 5-9.

Halstead S B, Heinz F X, Barrett A D T, Roehrig J T. 2005. Dengue virus: molecular basis of cell entry and pathogenesis 25-27 June 2003, Vienna, Austria. Vaccine, 23: 849-856.

Halstead S B, Durbin A P, Whitehead S S, Shaffer D, Elwood D, Wanionek K, Thumar B, Blaney J E, Murphy B R, Schmidt A C. 2011. A Single Dose of the DENV-1 Candidate Vaccine rDEN1 $\Delta 30$ Is Strongly Immunogenic and Induces Resistance to a Second Dose in a Randomized Trial. PLOS Negl Trop Dis, 5: e1267.

Hanley K A, Lee J J, Blaney J E, Murphy B R, Whitehead S S. 2002. Paired charge-to-alanine mutagenesis of dengue virus type 4 NS5 generates mutants with temperature-sensitive, host range, and mouse attenuation phenotypes. J Virol, 76: 525-531.

Harenberg A, Begue S, Mamessier A, Caillet C, Guy B. 2013. Persistence of $\mathrm{Th} 1 / \mathrm{Tc} 1$ responses one year after tetravalent dengue vaccination in adults and adolescents in Singapore. Hum Vacc Immunother, 9: 2317-2325.

Huang C Y, Butrapet S, Tsuchiya K R, Bhamarapravati N, Gubler D J, Kinney R M. 2003. Dengue 2 PDK-53 Virus as a Chimeric Carrier for Tetravalent Dengue Vaccine Development. J Virol, 77: 11436-11447.

Huang C Y, Kinney R M, Livengood J A, Bolling B, Osorio J E, Stinchcomb D T. 2013. Genetic and Phenotypic Characterization of Manufacturing Seeds for a Tetravalent Dengue Vaccine (DENVax). PLOS Negl Trop Dis, 7: e2243.

Hui Lu, XiaoFeng Xu, Na Gao, An J. 2013. Preliminary evaluation of DNA vaccine candidates encoding dengue $-2 \mathrm{prM} / \mathrm{E}$ and NS1: Their immunity and protective efficacy in mice. Mol Immunology, 54: 109-114.

Innis B L, Eckels K H. 2003. Progress in development of a liveattenuated, tetravalent dengue virus vaccine by theUnited States Army Medical Research and Materiel Command. Am J Trop Med Hyg, 69: 1-4.

Kitchener S, Nissen M, Nasveld P, Forrat R, Saluzzo J F. 2006. Immunogenicity and safety of two live-attenuated tetravalent dengue vaccine formulations in healthy Australian adults. Vaccine, $24: 1238-1241$.

Lang J. 2012. Development of Sanofi Pasteur tetravalent dengue vaccine. Rev Inst Med Trop Sao Paulo, 54: S15-S17.

Leo Y S, Wilder-Smith A, Archuleta S, Shek L P, Chong C Y. 2012. Immunogenicity and safety of recombinant tetravalent dengue vaccine (CYD-TDV) in individuals aged 2-45 years Phase II randomized controlled trial in Singapore. Hum Vacc Immunother, 8: 1259-1271.

Letson G W, Singhasivanon P, Fernandez E, Abeysinghe N, Amador J J, Margolis H S, Edelman R. 2010. Dengue vaccine trial guidelines and role of large-scale, post proof-of-concept demonstration projects in bringing a dengue vaccine to use in dengue endemic areas. Human Vaccines, 6: 802-809.

Lu H, Xu X, Gao N, An J. 2013. Preliminary evaluation of DNA vaccine candidates encoding dengue- $2 \mathrm{prM} / \mathrm{E}$ and NS1: Their immunity and protective efficacy in mice. Molecular Immunology, 54: 109-114.

Mahoney R, Chocarro L, Southern J, Francis D P, Vose J, Margolis H. 2011. Dengue Vaccines Regulatory Pathways: A Report on Two Meetings with Regulators of Developing Countries. PLoS Medicine, 8: e1000418.

Mani S, Tripathi L, Raut R, Tyagi P, Arora U, Barman T, Sood R, Galav A, Silva A D, Swaminathan S. 2013. Pichia pastoris-Expressed Dengue 2 Envelope Forms Virus-Like Particles without 
Pre-Membrane Protein and Induces High Titer Neutralizing Antibodies. PLoS one, 8: e64595.

McArthur J H, Durbin A P, Marron J A, Wanionek K A, Murphy B R, Whitehead S S. 2008. Phase I Clinical Evaluation of rDEN4 $\triangle 30-200,201$ : A Live Attenuated Dengue 4 Vaccine Candidate Designed for Decreased Hepatotoxicity. Am J Trop Med Hyg, 79: 678-684.

McKeage K, Romanowski B. 2011. AS04-adjuvanted human papillomavirus (HPV) types 16 and 18 vaccine (Cervarix $(\mathbb{B})$ : a review of its use in the prevention of premalignant cervical lesions and cervical cancer causally related to certain oncogenic HPV types. Drugs, 71: 465-488.

McKenzie A, Watt M, Gittleson C. 2010. ISCOMATRIXTM vaccines: safety in human clinical studies. Hum Vaccin, 6: 237-246.

Men R, Bray M, Clark D, Chanockrober M, Lai C-J. 1996. Dengue Type 4 Virus Mutants Containing Deletions in the 39 Noncoding Region of the RNA Genome: Analysis of Growth Restriction in Cell Culture and Altered Viremia Pattern and Immunogenicity in Rhesus Monkeys. J Virol, 70: 3930-3937.

Morel S, Didierlaurent A, Bourguignon P, Delhaye S, Baras B, Jacob V, Planty C, Elouahabi A, Harvengt P, Carlsen H, Kielland A, Chomez P, Garçon N, Van M M. 2011. Adjuvant System AS03 containing $\alpha$-tocopherol modulates innate immune response and leads to improved adaptive immunity. Vaccine, 29: 2461-2473.

Normile D. 2013. Surprising New Dengue Virus Throws A Spanner in Disease Control Efforts. Scinece, 342: 415.

Osorio J E, Brewoo J N, Silengo S J, Arguello J, Stinchcomb D T. 2011. Efficacy of a Tetravalent Chimeric Dengue Vaccine (DENVax) in Cynomolgus Macaques. Am J Trop Med Hyg, 84: 978-987.

Poo J, Galan F, Forrat R, Zambrano B, Lang J, Dayan G H. 2011. Live-attenuated tetravalent dengue vaccine in dengue-naïve children, adolescents, and adults in mexico city: randomized controlled phase 1 trial of safety and immunogenicity. Pediatr Infect Dis J, 30: e9-17.

Putnak R, Barvir D A, Burrous J M, Dubois D R, D'Andrea V M, Hoke C H, Sadoff J C, Eckels K H. 1996. Development of a Purified, Inactivated, Dengue-2 Virus Vaccine Prototype in Vero Cells: Immunogenicity and Protection in Mice and Rhesus Monkeys. J Infect Dis, 174: 1176-1184.

Raviprakash K, Porter K R, Kochel T J, Ewing D, Simmons M, Phillips I. 2000. Dengue virus type 1 DNA vaccine induces protective immune responses in rhesus macaques. J Gen Virol, 81: $1659-1667$.

Robert Putnak J, Coller B A, Voss G, Vaughn D W, Clements D, Peters I, Bignami G, Houng H-S, Chen R C M, Barvir D A, Seriwatana J, Cayphas S, Garçon N, Gheysen D, Kanesa-thasan N, McDonell M, Humphreys T, Eckels K H, Prieels J-P, Innis B L. 2005. An evaluation of dengue type-2 inactivated, recombinant subunit, and live-attenuated vaccine candidates in the rhesus macaque model. Vaccine, 23: 4442-4452.

Rodriguez-Roche R, Gould E A. 2013. Understanding the Dengue Viruses and Progress towards Their Control. BioMed Research International, 2013: 690835.

Rothman A L. 2011 Immunity to dengue virus: a tale of original antigenic sin and tropical cytokine storms. Nat Rev Immunol., 11: 532-543

Sabchareon A, Lang J, Chanthavanich P, Yoksan S, Forrat R, Attanath P, Sirivichayakul C, Pengsaa K, Pojjaroen-Anant C, Chokejindachai W, Jagsudee A, Saluzzo J F, Bhamarapravati N. 2002. Safety and immunogenicity of tetravalent live-attenuated dengue vaccines in Thai adult volunteers: role of serotype concentration, ratio, and multiple doses. Am J Trop Med Hyg, 66: 264-272.

Sabchareon A, Wallace D, Sirivichayakul C, Limkittikul K, Chan- thavanich P, Suvannadabba S, Jiwariyavej V, Dulyachai W, Pengsaa K, Wartel T A, Moureau A, Saville M, Bouckenooghe A, Viviani S, Tornieporth N G, Lang J. 2012. Protective efficacy of the recombinant, live-attenuated, CYD tetravalent dengue vaccine in Thai schoolchildren: a randomised, controlled phase 2b trial. Lancet, 380: 1559-1567.

Sanchez V, Thomas G N, Tomlinson B, Chan P K S, Thomas G N. 2006. Innate and adaptive cellular immunity in flavivirus-na"ive human recipients of a live-attenuated dengue serotype 3 vaccine produced in Vero cells (VDV3). Vaccine, 24: 4914-4926.

Sardesai N Y, Weiner D B. 2011. Electroporation delivery of DNA vaccines: prospects for success. Curr Opin Immun, 23: 421-429.

Simmons C P, Chau T N, Thuy T T, Tuan N M, Hoang D M, Thien N T. 2007. Maternal antibody and viral factors in the pathogenesis of dengue virus in infants. J Infect Dis, 196: 416-424.

Simmons M, Burgess T, Lynch J, Putnak R. 2010. Protection against dengue virus by non-replicating and live attenuated vaccines used together in a prime boost vaccination strategy. Virology, 396: 280-288.

Sinha G. 2014. Sanofi's dengue vaccine first to complete phase 3 . Nat Biotech, 32: 605-606.

Sun W, Nisalak A, Gettayacamin M, Eckels K H, Putnak J R, Vaughn D W, Innis B L, Thomas S J, Endy T P. 2006. Protection of Rhesus Monkeys against Dengue Virus Challenge following Tetravalent Live-attenuated Dengue Virus Vaccination. J Inf Dis, 193: $1658-1665$.

Sun W, Cunningham D, Wasserman S S, Perry J, Putnak J R, Eckels K H, Vaughn D W, Thomas S J, Kanesa-Thasan N, Innis B L, Edelman R. 2009. Phase 2 clinical trial of three formulations of tetravalent live-attenuated dengue vaccine in flavivirusnaive adults. Hum Vaccin, 5: 33-40.

Thisyakorn U, Thisyakorn C. 2014. Latest developments and future direction in dengue vaccines. Ther Adv Vacc, 2: 3-9.

Thomas S J. 2011. The necessity and quandaries of dengue vaccine development. J Infect Dis, 203: 299-303.

Thomas S J, Endy T P. 2011. Critical issues in dengue vaccine development. Curr Opin Infect Dis, 24: 442-450.

Thomas S J, Eckels K H, Carletti I, Gibbons R V, Innis B L. 2013. A Phase II, Randomized, Safety and Immunogenicity Study of a Re-Derived, Live-Attenuated Dengue Virus Vaccine in Healthy Adults. Am J Trop Med Hyg, 88: 73-88.

Upasana Arora, Poornima Tyagi, Sathyamangalam Swaminathan, Khanna N. 2013. Virus-like particles displaying envelope domain III of dengue virus type 2 induce virus-specific antibody response in mice. Vaccine, 31: 873-878.

Valdés I, Hermida L, Gil L, Lazo L, Castro J, Martín J, Bernardo L, López C, Niebla O, Menéndez T, Romero Y, Sánchez J, Guzmán M G, Guillén G. 2010. Heterologous prime-boost strategy in non-human primates combining the infective dengue virus and a recombinant protein in a formulation suitable for human use. Int J Infect Dis, 14: e377-e383.

Valdés I, Hermida L, Martín J, Menéndez T, Gil L, Lazo L, Castro J, Niebla O, López C, Bernardo L, Sánchez J, Romero Y, Martínez R, Guzmán M G, Guillén G. 2009a. Immunological evaluation in nonhuman primates of formulations based on the chimeric protein P64k-domain III of dengue 2 and two components of Neisseria meningitidis. Vaccine, 27: 995-1001.

Valdés I, Bernardo L, Gil L, Pavón A, Lazo L, López C, Romero Y, Menendez I, Falcón V, Betancourt L, Martín J, Chinea G, Silva R, Guzmán M G, Guillén G, Hermida L. 2009b. A novel fusion protein domain III-capsid from dengue-2, in a highly aggregated form, induces a functional immune response and protection in mice. Virology, 394: 249-258.

Valdes I, Gil L, Romero Y, Castro J, Puente P, Lazo L, Marcos E, Guzman M G, Guillen G, Hermida L. 2011. The Chimeric 
Protein Domain III-Capsid of Dengue Virus Serotype 2 (DEN2) Successfully Boosts Neutralizing Antibodies Generated in Monkeys upon Infection with DEN-2. Clin Vac Immun, 18: 455-459.

Van der Straten A, Johansen H, Rosenberg M, Sweet R W. 1989. Introduction and constitutive expression of gene products in cultured drosophila cells using hygromycin B selection. Meth Mol Cell Biol, 1: 1-8.

Villar L, Dayan G H, Arredondo-García J L, Saville M, Noriega F. 2014. Efficacy of a Tetravalent Dengue Vaccine in Children in Latin America. N Engl J Med. Epub ahead of print. DOI: 10.1056/NEJMoa1411037.

Voelker R. 2010. Race Is On for Effective Dengue Vaccine. JAMA, 304.

Wahala M P B, Silva A M d. 2011. The Human Antibody Response to Dengue Virus Infection. Viruses, 3: 2374-2395.

Wan S W, Lin C F, Wang S, Chen Y H, Yeh T M, Liu H S, Anderson R, Lin Y S. 2013. Current progress in dengue vaccines. J Biomed Sci, 20:37.

Watanaveeradej V, Simasathien S, Nisalak A, Endy T P, Jarman R G, Innis B L. 2011. Safety and Immunogenicity of a Tetravalent
Live-Attenuated Dengue Vaccine in Flavivirus-Naive Infants. Am J Trop Med Hyg, 85: 341-351.

Whitehead S S, Hanley K A, Jr. B J E, Gilmore L E, Elkins W R, Murphy B R. 2003. Substitution of the structural genes of dengue virus type 4 with those of type 2 results in chimeric vaccine candidates which are attenuated for mosquitoes, mice, and rhesus monkeys. Vaccine, 21: 4307-4316.

Whitehead S S, Falgout B, Hanley K A, Blaney J E, Markoff L, Murphy B R. 2003. A Live, Attenuated Dengue Virus Type 1 Vaccine Candidate with a 30-Nucleotide Deletion in the 3' Untranslated Region Is Highly Attenuated and Immunogenic in Monkeys. J Virol, 77: 1653-1657.

Wright P F, Durbin A P, Whitehead S S, Ikizler M R, Henderson S, Blaney J E. 2009. Phase 1 trial of the dengue virus type 4 vaccine candidate rDEN4\{Delta\}30-4995 in healthy adult volunteers. Am J Trop Med Hyg, 81: 834-841.

Zheng Q, Fan D, Gao N, An J. 2011. Evaluation of a DNA vaccine candidate expressing prM-E-NS1antigens of dengue virus serotype1with or without granulocyte-macrophagecolony-stimulating factor (GM-CSF) in immunogenicity and protection. Vaccine, 29: 763-771. 